\title{
SUPERVISI KEPALA SEKOLAH DAN PARTISIPASI GURU PJOK DALAM KKG TERHADAP KINERJA GURU PJOK SD NEGERI KECAMATAN KOTO TANGAH KOTA PADANG
}

\author{
Zulni Endrita ${ }^{1}$, Wilda Wellis ${ }^{2}$, Umar ${ }^{3}$. \\ zulni@fik.unp.ac.id, umarkepel@ fik.unp.ac.id, wilda@ fik.unp.ac.id \\ ${ }^{1}$ Mahasiswa Program Studi Pendidikan Olahaga (S2) \\ Universitas Negeri Padang \\ ${ }^{2}$ Pembimbing I (satu) \\ ${ }^{3}$ Pembimbing II (dua)
}

\begin{abstract}
Based on the observation made on both the principal and PJOK teachers in Sekolah Dasar Negeri Kecamatan Koto Tangah shows that performance of PJOK teachers which are owned are still low. Performance of PJOK teachers in Sekolah Dasar Negeri Kecamatan Koto Tangah influenced by many factors, some of them is allegedly affected by supervision the school principal and PJOK teachers participation in the KKG. This research aims to understand the influence of between variables supervision the school principal, PJOK teachers participation in KKG and performance of PJOK teachers.

Population in research it is a whole principals and PJOK teachers in Sekolah Dasar Negeri Kecamatan Koto Tangah in the academic year 2015 / 2016 which consisted of 58 people school principals and 80 people PJOK teachers. The technique of sampling is done by means of Total Sampling, with the sample that used as many as 58 people school principals and 80 people PJOK teachers. Data were collected using a questionnaire for the supervision of the principal and PJOK teachers participation in KKG as well as the results of performance assessment of PJOK teachers for PJOK teachers performance.

The results of the analysis of the data shows that: (1) The supervision of the principal effect on the performance of the PJOK teachers is $27.56 \%$. (2) The participation of the PJOK teachers in KKG that influence the performance of PJOK teachers is $16.72 \%$. (3) Supervision of the principal and PJOK teachers participation in KKG together have an effect on the performance of the PJOK teachers is $30.5 \%$.
\end{abstract}

Keywords : Supervision of The Principal, The Participation of The PJOK Teachers in KKG and The Performance of The PJOK Teachers. 


\section{PENDAHULUAN}

Pendidikan adalah salah satu bidang yang memegang peranan penting untuk membangun manusia Indonesia seutuhnya. Tujuan pendidikan pada dasarnya adalah meningkatkan kualitas sumber daya manusia, melalui peningkatan mutu pendidikan diupayakan tercapainya pem-bentukan profil manusia yang siap secara intelektual dan mental serta fisik dan rohani demi menghadapi masa depan yang semakin membutuhkan ilmu pengetahuan dan teknologi.

Peran serta guru dalam kaitan dengan mutu pendidikan menurut S.Nasution (2006:23) sekurang-kurangnya dapat dilihat dari empat dimensi yaitu guru sebagai pribadi, guru sebagai unsur keluarga, guru sebagai unsur pendidikan, dan guru sebagai unsur masyarakat.

Kinerja peran guru dalam kaitan dengan mutu pendidikan harus dimulai dengan dirinya sendiri. Sebagai pribadi, guru merupakan perwujudan diri dengan seluruh keunikan karakteristik yang sesuai dengan posisinya sebagai pemangku profesi keguruan.

Itulah sebabnya pendidi kan senantiasa memerlukan upaya perbaikan dan peningkatan sejalan dengan semakin tingginya kebutuhan dan tuntutan kehidupan masyarakat (Fattah 2000:1). Kunci utama keberhasilan pendidikan salah satunya terletak pada kualitas guru. Mengingat peran guru yang besar dalam proses pendidikan, kepala sekolah sebagai atasan langsung dituntut memiliki kapasitas utama sebagai edukator,manajer, administrator, supervisor, leader, inovator, dan motivator. Sementara itu guru memiliki tugas utama (1) membuat program pembelajaran; (2) melaksanakan program pembelajaran; (3) melaksanakan evaluasi; (4) melaksanakan analisis hasil belajar siswa; (5) melaksanakan perbaikan, remedial, dan pengayaan. Tidak semua guru mampu melaksanakan tugas utama itu.

Upaya untuk mening katkan kinerja guru PJOK yaitu melalui kegiatan supervisi juga terus diupayakan secara intensif. Pandangan yang lebih operasional, Nergery dalam Muslim (2009:38) menunjukkan bahwa kegiatan supervisi pendidikan merupakan salah satu cara pembinaan guru, memiliki posisi yang strategis bagi upaya peningkatan kinerja guru.

Secara umum hal yang mempengaruhi supervisi yang akan dilakukan kepala sekolah diantaranya umur, pengalaman bekerja dan kualifikasi pendidikan. Kepala sekolah harus menguasai semua bidang ilmu pendidikan dan mata pelajaran, jadi kualifikasi pendidikan kepala sekolah sangat menentukan kinerja kepala sekolah, ketika kepala sekolah melakukan supervisi sebaiknya kepala sekolah harus bisa menetapkan guru mata pelajaran sesuai bidang yang dikuasai. Untuk menjadi guru PJOK harus berasal dari pendidikan olahraga bukan dari guru mata pelajaran lain yang menguasai olahraga.

Pembinaan kinerja guru untuk mengetahui kompetensi yang dimiliki guru dilakukan pemerintah dengan acara mengadakan UKG (Uji Kompetensi Guru) ditiap daerah di seluruh Indonesia yang diadakan pada bulan November - Desember 2015. Sebanyak tujuh provinsi mendapat nilai terbaik dalam penyelenggaraan uji kompetensi guru (UKG) tahun 2015 tersebut. Nilai yang diraih merupakan nilai yang mencapai standar kompetensi minimum (SKM) yang ditargetkan secara nasional, yaitu rata-rata 55. Tujuh provinsi tersebut sebagai berikut:

1. DI Yogyakarta dengan nilai rata-rata UKG : 62,58

2. Jawa Tengah nilai rata-rata UKG : 59,10

3. DKI Jakarta : 58,44

4. Jawa Timur: 56,73 , 
5. Bali: 56,13

6. Bangka Belitung : 55,13

7. Jawa Barat : 55,06

Selain tujuh provinsi di atas yang mendapatkan nilai sesuai standar kompetensi minimum (SKM), ada tiga provinsi yang mendapatkan nilai di atas rata-rata nasional, tapi masih berada dibawah SKM yaitu 55, provinsi tersebut yaitu Kepulauan Riau $(54,72)$, Sumatera Barat $(54,68)$, dan Kalimantan Selatan $(53,15)$. Maka dari itu untuk meningkatkan nilai SKM yang masih di bawah rata-rata, peme rintah berupaya meningkatkan pembinaan kinerja (Kemendik -bud tahun 2016).

Pembinaan kinerja guru PJOK pada guru sekolah dasar berikutnya adalah dengan melalui kegiatan kelompok kerja. Robbins dalam Husdarta (2009:105) mendefinisikan kelompok kerja sebagai suatu kelompok yang berinteraksi terutama untuk berbagi informasi dan mengambil keputusan agar bisa membantu tiap anggota berkinerja dalam bidang sesuai tanggung jawab masing-masing. Guru akan semakin memiliki kompotensi professional, pedagogik, kepribadian, dan sosial, jika terlihat dalam kelompok kerja guru karena segala permasalahan yang berhubungan dengan kegiatan belajar mengajar akan terselesaikan karena mendapat bantuan dari pihak yang berkompeten.

Dengan mengikuti KKG guru memiliki wadah untuk menyampaikan kendala-kendala dalam pembelajaran yang dilaksanakannya. Kendala dalam pembelajaran itu kemudian dibahas oleh sesama guru. Bagi guru berkompeten diberikan kesempatan untuk memberikan solusi mengatasi permasalahan, sedangkan bagi guru lainnya akan mendapatkan masukan bila suatu saat menemukan permasalahan yang sama.

Uraian di atas menunjukan bahwa persepsi positif guru terhadap supervisi kepala sekolah dan partisipasi guru dalam KKG merupakan faktor yang cukup menentukan dalam upaya peningkatkan kinerja guru PJOK sehingga dapat diduga bahwa rendahnya kinerja guru PJOK Sekolah Dasar Negeri Kecamatan Koto Tangah disebabkan oleh adanya persepsi guru yang negatif terhadap kegiatan supervisi kepala sekolah, supervisi yang dilakukan kepala sekolah di sekolah sekarang banyak yang bersifat politik, kepala sekolah ditekan supaya baik dan rendahnya tingkat partisipasi guru dalam KKG. Atas dasar pemikiran tersebut, maka peneliti merasa tertarik untuk mengadakan penelitian tentang "Pengaruh Supervisi Kepala Sekolah dan Partisipasi Guru dalam KKG terhadap Kinerja Guru Pendidikan Jasmani, Olahraga dan Kesehatan di Sekolah Dasar Negeri Kecamatan Koto Tangah Kota Padang”.

\section{METODE PENELITIAN}

Metode yang digunakan dalam penelitian ini adalah menggunakan pendekatan ex post facto. Jadi dalam penelitian ini tidak mengadakan perlakuan terhadap variabel penelitian melainkan mengkaji fakta-fakta yang telah terjadi dan pernah dilakukan oleh subjek penelitian.

Artinya memanipulasi terha -dap variabel penelitian tidak dilakukan, namun hanya menggali fakta-fakta dengan menggunakan angket yang berisi sejumlah pernyataan/pernyataan yang merefleksikan persepsi mereka terhadap variabel yang diteliti.

Melalui penelitian ini dapat diketahui pengaruh variasi dalam sebuah variabel dengan lainnya. Penelitian ini menempatkan supervisi kepala sekolah, partisipasi guru dalam KKG sebagai variabel independen dan kinerja guru PJOK sebagai variabel dependen. Penelitian ini dilaksanakan di SD Negeri Kecamatan Koto Tangah Kota Padang. Sedangkan waktu penelitian 
dilaksanakan pada bulan April 2016. Populasi penelitian ini adalah seluruh Guru Olahraga dan Kepala Sekolah SD Negeri Kecamatan Koto Tangah Kota Padang yang berjumlah 80 orang dari Olah raga dan 58 orang dari Kepala Sekolah. sampel dari penelitian ini adalah seluruh populasi. Instrumen dalam penelitian berupa kuisioner dengan skala yang digunakan dalam penyebaran kuesioner/angket adalah Skala Likert. Teknik pengumpulan data dalam penelitian ini dilakukan melalui penyebaran kuesioner/ angket untuk supervisi kepala sekolah dan partisipasi guru PJOK dalam KKG.

\section{HASIL PENELITIAN DAN PEMBAHASAN}

Berdasarkan hasil pengujian yang telah diuraikan bahwa supervisi kepala sekolah $\left(\mathrm{X}_{1}\right)$ dan partisipasi guru PJOK dalam KKG, berpengaruh secara signifikan terhadap kinerja guru (Y). Uraian selengkapnya adalah sebagai berikut:

\section{Supervisi Kepala Sekolah Berpengaruh terhadap Kinerja Guru PJOK}

Dari hasil analis data dapat dibuktikan bahwa supervisi kepala sekolah (X1) berpengaruh besar terhadap kinerja guru PJOK (produktivitas kerja). Besarnya pengaruh tersebut dapat dinyatakan oleh besarnya koefisien determinasi $27.56 \%$. Dibandingkan dengan variabel-variabel bebas lainnya dalam penelitian ini, maka variabel supervisi kepala sekolah adalah memiliki pengaruh besar terhadap kinerja guru PJOK. Hal ini dapat dipahami karena supervisi kepala sekolah atau dalam organisasi sosial memiliki peran yang sangat penting dalam menggerakan roda organisai.

Berdasarkan butir-butir soal dalam angket supervisi kepala sekolah dapat kita simpulkan bahwa supervisi yang dilakukan kepala sekolah cukup baik terutama pada kemampuan kepala sekolah dalam melak sanakan identifikasi sebelum kegiatan supervisi, kunjungan kelas/lapangan yang dilakukan kepala sekolah, kemampuan kepala sekolah dalam menga -mati guru PJOK mengajar, Supervisi Kepala Sekolah dilakukan secara terencana, Kotinyu, sistematis, dan prosedural, Supervisi Kepala Sekolah berfokus terhadap peningkatan kualitas proses belajar-mengajar.

Penelitian ini sejalan dengan penelitian yang dilakukan oleh Imran mengenai pembinaan guru sekolah dasar oleh kepala sekolah melalui supervisi di Malang (2005). Hasil penelitian ini menunjukan bahwa rata-rata kepala sekolah mengalami kesulitan dalam melakukan pembinaan terhadap guru melalui supervisi dengan teknik kun -jungan kelas, menggunakan pertemuan pribadi, rapat dewan guru, menggunakan teknik kunjungan sekolah, pertemuan kelompok-kelompok dan melalui penerbitan bulletin professional. Sedangka faktor-faktor yang menyebabkan kesulitan kepala sekolah dalam melakukan professional, terbatasnya waktu, terbatasnya petunjuk pelaksanaan dan terbatasnya biaya dalam Supardi (2013:224)

Beranjak dari temuan penelitian di atas maka dapat ditarik kesimpulan bahwa terdapat pengaruh yang signifikan antara variabel supervisi kepala sekolah terhadap kinerja guru PJOK. Semakin baik supervisi kepala sekolah di Sekolah Dasar Negeri Kecamatan Koto Tangah maka semakin besar pengaruhnya terhadap kinerja guru PJOK, hal ini diperoleh dengan cara sungguh-sungguh untuk kinerja yang baik dari guru PJOK. 
Ketika kinerja guru PJOK baik, maka proses supervisi yang harus dilakukan oleh kepala sekolah harus baik. Serta kinerja guru PJOK yang baik akan berpengaruh positif terhadap proses pembelajaran yang dilakukan di sekolah.

\section{Partisipasi guru PJOK dalam KKG Berpengaruh Terhadap Kinerja guru PJOK}

Telah diketahui bahwa besarnya variabel partisipasi guru PJOK dalam KKG (X2) terhadap kinerja guru PJOK (Y) yang dihitung berdasarkan koefisien korelasi $\left(\mathrm{r}_{\mathrm{y} 2}\right)$ adalah sebesar 0.050 atau koefisien determinasi $\left(\mathrm{r}^{2}\right)$ sebesar $16.72 \%$. Hal ini berarti bahwa partisipasi guru PJOK dalam KKG merupakan variabel yang memiliki pengaruh besar terhadap kinerja guru PJOK.

Hal ini dapat dipahami bahwa ketika seorang guru PJOK berpartisipasi aktif dalam KKG maka wawasannya akan semakin bertambah. Disisi lain pola pikirnya juga akan berubah kearah yang positif. Dengan demikian kinerja mereka juga akan semakin meningkat seiring dengan meningkatnya kinerja mereka sebagai guru.

Berdasarkan butir-butir soal dalam partisipasi guru PJOK dalam KKG dapat kita simpulkan bahwa partisipasi yang dilakukan guru PJOK cukup baik terutama pada tingkat kehadiran guru PJOK dalam kegiatan KKG, keter -libatan guru PJOK dalam mengemukakan permasalahan, keterlibatan guru PJOK dalam pembuatan program semester, keterlibatan guru PJOK dalam pembuatan program tahunan, keterlibatan guru PJOK dalam penyusunan silabus, keterlibatan guru PJOK dalam pembuatan rencana program pembelajaran, dan keterlibatan guru PJOK dalam pendalaman materi.

Beranjak dari temuan penelitian di atas maka dapat ditarik kesimpulan bahwa terdapat pengaruh yang signifikan partisipasi guru PJOK dalam KKG terhadap kinerja guru PJOK.

3. Supervisi Kepala Sekolah dan Partisipasi guru PJOK dalam KKG secara bersamasama berpengaruh secara signifikan terhadap Kinerja Guru PJOK

Pengaruh yang signifikan antara supervisi kepala sekolah dan partisipasi guru PJOK dalam KKG secara bersama dengan kinerja guru PJOK. Berdasarkan hasil perhitungan analisis regresi ganda (multiple regression) diperoleh dari analisis tabel tersebut Rsquare adalah 0.017 yang merupakan kuadrat dari 0.553 atau $0.553^{2}$. Skor inilah merupakan koefisien ditermi -nasi, yang artinya $30.5 \%$ kontribusi ditentukan oleh variabel supervisi kepala sekolah dan partisipasi guru PJOK dalam KKG sedangkan sisanya $69.5 \%$ dipengaruhi oleh sebab-sebab lainnya (selain variabel yang tidak diteliti dalam penelitian ini). Jadi, supervisi kepala sekolah dan partisipasi guru PJOK dalam KKG secara bersamasama memeberikan kontribusi terhadap kinerja guru PJOK sebesar $30.5 \%$.

Pengaruh yang besar supervisi kepala sekolah terhadap kinerja guru PJOK (produktivitas kerja), meng -isyaratkan bahwa supervisi kepala sekolah berperan sangat penting dalam menentukan kualitas kinerja guru PJOK disekolah. Sehingga pelaksanaan kegiatan supervisi yang sistematis dan mendidik sangat perlu dilaksanakan dalam rangka peningkatan kualitas kinerja guru.

Disisi lain tidak dipungkiri bahwa seseorang belajar untuk meningkatkan kemampuannya dalam bekerja. Bertambahnya wawasan kepen -didikan dan perubahan 
pola pikir sebagai hasil belajar akan sangat berpengaruh positif terhadap peningkatan kualitas kinerja guru PJOK.

Oleh sebab itu guru harus berusaha meningkatkan kompe tensinya melalui partisipasinya dalam KKG dan peningkatan jenjang pendidikan. Karena dengan ditunjang supervisi kepala sekolah yang baik dan semakin meningkatnya partisi pasi guru PJOK dalam KKG akan berpengaruh secara positif terhadap kinerja guru PJOK.

Kegiatan supervisi kepala sekolah dapat membantu dan melayani guru melalui penciptaan lingkungan yang kondusif bagi peningkatan kualitas pengetahuan, kete rampilan, sikap, kedisiplinan, serta pemenuhan kebutuhan meliputi: (1) merencanakan supervisi, (2) merumuskan tujuan supervisi, (3) meru muskan prosedur supervisi, (4) menyusun format observasi, (5) berunding dan bekerjasama dengan guru, (6) mengamati guru mengajar, (7) menyim pulkan hasil supervisi, (8) mengkonfirmasikan supervisi untuk keperluan mengambil langkah tindak lanjut, menurut Sahertian dalam Priansa (2014:125).

Penelitian ini sejalan dengan penelitian tentang faktor-faktor yang mempengaruhi kinerja guru pendidikan Jasmani di sekolah dasar oleh Husdarta (2007). Hasil penelitian menun jukan terdapat pengaruh layanan supervisi terhadap kinerja guru pendidikan jasmani secara signifikan dan positif dalam Supardi (2013:228).

Ketika kinerja guru PJOK baik, maka proses supervisi yang harus dilakukan oleh kepala sekolah dan partisipasi guru PJOK dalam KKG harus baik pula agar proses pembelajaran agar berjalan dengan baik.

\section{KESIMPULAN DAN SARAN}

\section{Kesimpulan}

Berdasarkan analisis data dan pengujian hipotesis dapat diambil kesimpulan sebagai berikut :

1. Supervisi kepala sekolah berpengaruh positif terhadap kinerja guru PJOK. Supervisi kepala sekolah yang dilakukan dengan baik maka kinerja akan meningkat, demikian pula sebaliknya. Supervisi kepala sekolah tidak dilakukan dengan baik, mengakibatkan kinerja guru PJOK rendah.

2. Partisipasi guru PJOK dalam KKG berpengaruh positif terhadap kinerja guru PJOK. Partisipasi guru PJOK dalam KKG yang dilakukan dengan baik maka kinerja guru PJOK akan meningkat demikian pula sebaliknya. Partisipasi guru PJOK dalam KKG tidak dilakukan dengan baik, kinerja guru PJOK rendah.

3. Supervisi kepala sekolah dan Partisipasi guru PJOK dalam KKG berpengaruh positif terhadap kinerja guru PJOK. Jika supervisi kepala sekolah dan Partisipasi guru PJOK dalam KKG secara bersama-sama dilakukan dengan baik maka kinerja guru PJOK akan baik, demikian pula sebaliknya jika supervisi kepala sekolah dan Partisipasi guru PJOK dalam KKG dilakukan dengan tidak baik maka kinerja guru PJOK akan tidak baik pula (buruk).

\section{Saran}

Berdasarkan temuan penelitian dan implikasi penelitian, maka dikemukakan saransaran sebagai berikut:

1. Kepada guru PJOK diharapkan untuk dapat meningkatkan kinerjanya dalam proses pembelajaran yang diberikan kepada siswa dalam upaya mencapai hasil kinerja yang optimal. 
2. Diharapkan kepada kepala sekolah perlu adanya supervisi setiap satu bulan sekali kepada guru PJOK agar lebih meningkatkan pengawasan tentang kinerja guru PJOK.

3. Sebaiknya penilaian partisipasi guru PJOK dalam KKG dinilai oleh pengawas masingmasing kelompok dalam KKG bukan oleh kepala sekolah setiap sekolah.

4. Bagi peneliti lainnya untuk dapat melakukan penelitian lanjutan dengan mengkaji faktorfaktor lain yang mempengaruhi kinerja guru PJOK seperti supervisi kepala sekolah, partisipasi guru PJOK dalam KKG, dan lainnya sehingga menambah cakrawala dan wawasan menjadi lebih luas.

\section{DAFTAR RUJUKAN}

Dikmenum. 2008. Kinerja Guru Indonesia. www.dikmenum.go.id (21 Januari. 2016).

Fattah, Nanang. 2000. Manajemen Berbasis Sekolah. Bandung: Andika.

Husdarta. 2009. Menajemen Pendidikan Jasmani.Bandung: Alfabeta

Muslim Banun, Sri. 2009. Supervisi Pendidikan Meningkatkan Kualitas Profesional Guru. Mataram: Alfabeta

Nasution, S. 2006. Azas-Azas Kurikulum. Jakarta: Bumi Aksara Hasbullah. (2012). Dasardasar Ilmu Pendidikan. Jakarta : Raja Grafindo Persada.

Oliva, P.F. 1987. Supervision for Today's School. New York: Longman, Inc.

PP RI No 19 Tahun 2005. 2006. Standar Nasional Pendidikan. Jakarta: Sinar Gra Ismaryati. (2008). Tes dan Pengukuran Olahraga. Surakarta: UNS Press

Priansa.2014.Manajemen Supervisi dan Kepemimpinan Kepala Sekolah. Bandung:Alfabeta

Sahertian, Piet A. 2008. Konsep Dasar dan Teknik Supervisi Pendidikan. Jakarta: Rineka Cipta.

Supardi.2013.Kinerja Guru. Jakarta: PT RajaGrafindo Persada.

Undang-Undang Guru dan Dosen Tahun 2005. 2006. Jakarta: Sinar Grafika Offset 